\title{
Delirium Management in the ICU
}

Michael E. Reznik, $M D^{1,2, *}$

Arjen J. C. Slooter, $M D, P h D^{3}$

\author{
Address \\ ${ }^{1}$ Departments of Neurology \& Neurosurgery, Alpert Medical School, Brown Uni- \\ versity, Providence, RI, USA \\ ${ }^{*}$ 2Division of Neurocritical Care, Rhode Island Hospital, 593 Eddy Street, APC 712, \\ Providence, RI, 02903, USA \\ Email:michael_reznik@brown.edu \\ ${ }^{3}$ Department of Intensive Care Medicine, University Medical Center Utrecht Brain \\ Center, Utrecht University, Utrecht, the Netherlands
}

Published online: 14 November 2019

(C) Springer Science+Business Media, LLC, part of Springer Nature 2019

This article is part of the Topical Collection on Critical Care Neurology

Keywords ICU delirium • Delirium management

\begin{abstract}
Purpose of review Delirium occurs frequently in critically ill patients and is associated with adverse outcomes in both the short and long term. In this review, we aim to highlight recent study findings on the prevention and treatment of delirium, provide additional recommendations based on expert guidelines, and indicate knowledge gaps deserving of future study.

Recent findings Multicomponent non-pharmacologic interventions have been shown to be efficacious in non-ICU populations, and multicomponent strategies such as the ABCDEF bundle have been adopted in the ICU with several studies showing a potential benefit in delirium outcomes. Meanwhile, two negative randomized clinical trials of antipsychotics in ICU patients (REDUCE and MIND-USA) have provided strong evidence that such medications neither prevent nor shorten the duration of delirium. Other potential pharmacologic treatments with promising results include dexmedetomidine and, to a lesser extent, ramelteon, but more data is needed before they may be more definitively recommended. Summary Effective and proven delirium management strategies are still largely lacking, though there is evidence to support the use of some non-pharmacologic interventions. Future studies of novel non-pharmacologic interventions and pharmacologic agents other than antipsychotics are warranted.
\end{abstract}




\section{Introduction}

Delirium is an acute disorder of consciousness and cognitive function that occurs frequently in critical care settings, with an incidence of nearly one-third according to a large meta-analysis of over 16,000 ICU patients [1]. However, rates as high as $80 \%$ or greater have previously been described in patients who are mechanically ventilated $[2,3]$, though modern ICU management strategies have reduced these rates considerably. Its impact is also far-reaching, as it has been shown to be associated with adverse outcomes in both the short and long-term. In the short-term, patients who develop delirium have a significantly longer duration of mechanical ventilation and longer ICU length of stay, as well as an over twofold higher risk of hospital mortality [1]. In the long-term, patients who had delirium during their ICU admission also had higher rates of mortality up to 12 months after hospitalization and were more likely to have long-term cognitive impairment [4-6]. However, some of these associations may not represent the independent effects of delirium itself $[7,8]$. There is controversy as to whether delirium is simply a marker of vulnerability or illness severity, whether the effect of delirium is solely related to its precipitating factors, or whether delirium is causally related to worse outcomes. Ultimately, all of these hypotheses are likely to be true to some degree [9].

The pathophysiology of delirium is poorly understood. Multiple factors play a role in its development arising from the interface of acute precipitating factors with each patient's underlying degree of vulnerability. A patient with a high degree of vulnerability due to a relatively low cognitive reserve (i.e., dementia) likely requires a less severe precipitating factor to develop delirium than does a patient who is less vulnerable $[10,11]$. On the other hand, the heterogeneity of the condition also suggests that there may be a wide variety of potential underlying mechanisms that may be implicated. Proposed mechanisms include neurotransmitter imbalances, such as reduced cholinergic activity [12] or dopamine and serotonin excess [13], neuronal network alterations with diminished functional connectivity [14], and neuroinflammation with blood-brain barrier breakdown [15]. As a result of this heterogeneity, uniform management strategies for delirium have proven elusive, suggesting that delirium management may ultimately benefit from more tailored approaches based on patient population and individual patient characteristics. Management of neurocritical care patients in particular may warrant different treatment compared with patients in general medical or surgical ICUs. We aim to review existing evidence and clinical practice guidelines and to provide recommendations for delirium management based on recent literature.

\section{Diagnostic evaluation}

\section{Delirium diagnosis and screening}

Delirium management hinges on accurate and timely detection. Referencestandard diagnostic criteria have been updated over several iterations of the Diagnostic and Statistical Manual (DSM) of Mental Disorders, with the most recent 5th edition prioritizing disturbances in attention and awareness that typically develop over a short period of time with a tendency to fluctuate [16]. Additional delirium symptoms that may occur include alterations of arousal, disorientation, disorganized thinking, inappropriate speech or mood, sleep-wake cycle disturbances, hallucinations, and psychomotor changes (increased and/or decreased activity depending on motor subtype).

Delirium screening tools have been developed specifically for the ICU from DSM-based criteria; the most widely used of which include the Confusion Assessment Method for the Intensive Care Unit (CAM-ICU) [2] and the Intensive Care Delirium Screening Checklist (ICDSC) [17]. Each has been extensively validated in research settings, though their accuracy is likely lower in real-world usage [18]. Certain populations remain especially challenging, including 
patients with hypoactive delirium [18], those with neurological critical illness [18], and patients with dementia [19].

Because of the variable presentations of delirium and its often fluctuating course, the chances of successful detection may be improved with multiple clinical examinations over the course of a day. Such encounters should be supplemented with standardized chart review [20], interviews with patients' family members, and discussion with bedside ICU nurses.

A high index of suspicion should especially be given to patients with recognized risk factors for delirium, including older age, a history of dementia, a significant degree of co-morbid illness, and higher overall illness severity [21, 22]. High-risk patients can be identified with various prediction models that incorporate lab values, medication use, and other factors, such as the E-PREDELIRIC model based on variables available at ICU admission [23] and the PRE-DELIRIC model based on variables present within $24 \mathrm{~h}$ of ICU admission [24].

\section{Identifying and addressing possible sources}

By definition, delirium represents a manifestation of an underlying medical condition or other triggering event [16], though such triggers may not always be immediately apparent. As such, it is important to perform a comprehensive clinical evaluation to identify possible sources. This includes a detailed history (with emphasis on alcohol, drug, and medication use) and physical examination, along with a focused diagnostic work-up as indicated by the clinical scenario (Table 1). In such cases, a patient's delirium is unlikely to resolve without first addressing the inciting issue.

\section{Non-pharmacologic strategies}

Non-pharmacologic strategies are a foundation of delirium management and should generally be attempted prior to pharmacologic interventions. Their aim is to mitigate environmental factors, restore the patient's own awareness of their environment, and promote multi-disciplinary cooperation in each patient's care.

\section{Table 1. Common causes of delirium in hospitalized and critically ill patients}

- Adverse medication effect/interaction

- Drug or other toxicity

- Medication or alcohol withdrawal

- Infection

- Electrolyte disturbance (e.g., hypo-/hypernatremia, hypo-/hyperglycemia, hypo-/hypercalcemia)

- Organ failure (e.g., uremia, respiratory failure, liver failure)

- New intracranial process

- Sleep/wake disturbance

- Pain/discomfort

- Dehydration

- Urinary or bowel retention 
Non-pharmacologic multicomponent interventions have been studied more extensively in hospitalized non-ICU patients than in the critically ill and represent the most effective way to prevent delirium and shorten its duration when it does occur in this setting. One of the earliest and most widely used approaches is based on the Hospital Elder Life Program (HELP), which emphasizes frequent reorientation and cognitive stimulation, early mobilization, sleep optimization (using noise-reduction strategies and relaxation techniques), early recognition and correction of vision and hearing impairment (with eyeglasses and hearing aids as available), and prevention of dehydration [25]. Recent meta-analyses of HELP [26] and other multicomponent non-pharmacologic interventions [27] concluded that such strategies reduced the odds of incident delirium in hospitalized non-critically ill patients by approximately half. Data supporting their effectiveness in treating delirium once it does occur is more limited, as there is a paucity of evidence showing a significant effect on delirium duration or severity [28].

However, though these strategies are also often adapted for the use of critically ill patients, a recent systematic review and meta-analysis suggest that current evidence does not necessarily support the empiric use of such nonpharmacologic interventions to prevent delirium in the ICU [29•]. Still, because of the success of such interventions in other patient populations and their relatively low risk, the Society of Critical Care Medicine's clinical practice guidelines does advocate for the use of multicomponent non-pharmacologic interventions focused on reducing modifiable risk factors for delirium, improving cognition, and optimizing sleep, mobility, hearing, and vision in critically ill

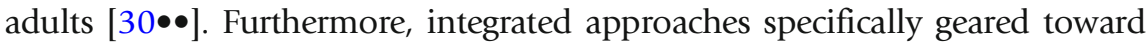
the management of mechanically ventilated patients have proven useful, with the most widely used of these being the ABCDEF bundle [31] (Table 2). Initially focusing on the "wake up and breathe" aspects of the first three ABC components, this bundle has been expanded to emphasize the importance of delirium management and two additional components that may have an impact on the development of delirium-early mobility and family engagement. It has the advantage of being applicable to any ICU patient at any time but is of particular relevance early in the course of a patient's ICU admission given its focus on prevention.

Though the ABCDEF bundle has not been formally tested in clinical trials, there is abundant evidence from clinical practice that it is safe and effective in

\section{Table 2. Components of the integrated $A B C D E F$ bundle for mechanically ventilated patients}

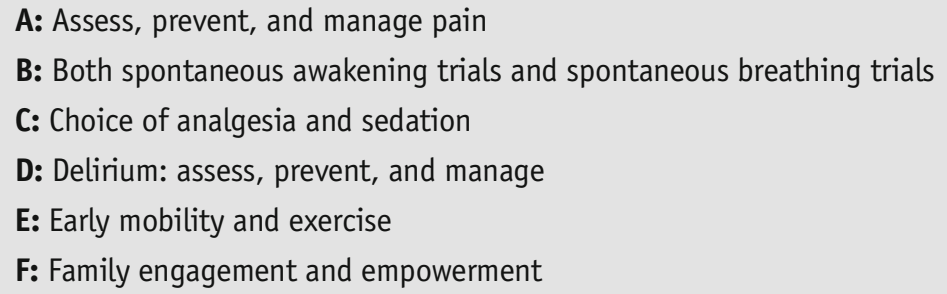


improving delirium outcomes in real-world settings $[32,33]$. These findings were confirmed in a recent prospective multicenter cohort of over 15,000 adults from the ICU Liberation Collaborative, in which the use of the ABCDEF bundle was associated with a reduced incidence of delirium along with improvements in other patient-centered outcomes [34•]. Though widespread compliance with all of the bundle's individual components remains a work in progress [35], even partial compliance may improve delirium rates and even overall survival [33, $34 \bullet]$.

Early mobility

Patients with delirium are at risk of developing numerous complications, including infections like pneumonia and urinary tract infections, pressure ulcers, venous thromboembolism, and overall deconditioning. Strategies to prevent such complications emphasize early mobilization and rehabilitation, including in patients who are mechanically ventilated, and there is data to suggest that physical and occupational therapy may also reduce delirium burden in the ICU. In one trial of mechanically ventilated ICU patients, those who received early mobilization with physical and occupational therapy had a significantly shorter duration of delirium than those who did not (median 2 vs. 4 days) [36]. In another randomized controlled pilot study, non-ventilated older ICU patients who received twice-daily occupational therapy had a significantly lower delirium incidence and duration than patients who received usual care [37]. As such, the Society of Critical Care Medicine's clinical practice guidelines recommend that critically ill patients receive interventions geared

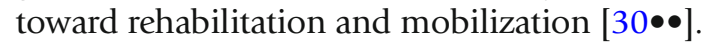

The ICU is an especially busy environment, with frequent clinical assessments, nursing care, procedures, lab draws, and other diagnostic testing superimposed on prominent background noise and artificial lighting. Environmental factors may indeed play a role in the development of delirium, and interventions such as single ICU rooms with improved daylight exposure may reduce delirium duration according to one small study [38]. By extension, overall sleep hygiene should also be maintained as circumstances allow. This includes maximizing natural light during daytime hours while keeping rooms dark at night and minimizing overnight medical and nursing procedures if possible. Additionally, the use of earplugs at night appears to significantly decrease delirium risk according to a meta-analysis of five intervention studies [39].

Physical restraints represent another external factor commonly used in the ICU, especially in patients who are restless or agitated and therefore at risk of inadvertently removing lines or tubes. Unfortunately, restraints themselves may contribute to worsening agitation, and there is evidence to suggest that the use of physical restraints may be associated with persistent delirium [40], although it is unclear whether this phenomenon is a cause or a consequence of their use. They should be minimized whenever possible, while lines and tubes should likewise be minimized as soon as they are no longer needed. Ultimately, once patients' critical illness resolves, they should be transferred out of the ICU as early as medically feasible in order to minimize these external factors. 
Frequent reorientation is a common part of multicomponent interventions, and nursing-based reorientation strategies-for example, the presence of clocks in each patient's room, reminding patients about their location and details of their illness, and memory-stimulation activities-may indeed decrease the incidence of ICU delirium according to one study [41]. Additionally, if family members are present, they may also provide valuable cues to improve a patient's awareness, and their involvement in a patient's care should be encouraged. The results of a small pilot study suggested that even automated reorientation messages recorded by a family member might result in more deliriumfree days [42].

Geriatrics consultation

There may be some benefit to proactive consultation of a geriatrics service in certain cases to assist with the clinical management of older patients. In two trials of early geriatrician consults in older patients with hip fracture, delirium incidence was reduced by over one-third compared with patients who received usual care $[43,44]$. This has led to the widespread use of combined geriatricsorthopedics services as a result, though it is unclear whether these findings can be extrapolated to critical care settings such as general medical/surgical ICUs or more focused subspecialty ICUs (i.e., neurocritical care units).

\section{Pharmacologic considerations}

Though potential pharmacologic interventions for delirium have been studied more extensively over the last several decades, truly effective medications have yet to be identified. A recent Cochrane review found no clear evidence to support the use of antipsychotics, cholinesterase inhibitors, melatonin, or other medications with the express purpose to prevent delirium in hospitalized patients [28]. Furthermore, though some medications may help treat symptoms of agitation, they do not necessarily reduce delirium duration and instead may shift a patient's delirium into the hypoactive spectrum. This lack of generalizable efficacy may be in part due to the heterogeneous nature of the condition, with a host of possible underlying etiologies, mechanisms, and clinical manifestations that may benefit from more tailored approaches in future studies.

Dopamine excess has long been thought to play a role in the pathogenesis of delirium [45]. As a result, antipsychotic medications that function as dopamine receptor antagonists have been a focus of studies aimed at identifying potential delirium treatments. However, several recent trials have provided compelling evidence that antipsychotic medications do not serve to prevent or shorten the clinical course of delirium in the ICU.

In the REDUCE study, a large multicenter randomized trial for critically ill ICU patients deemed to be at high risk of delirium $(n=1789$ patients); prophylactic intravenous haloperidol was not associated with any difference in patient survival at 28 days compared with placebo nor was there any difference in delirium incidence or delirium duration [46••]. In the MIND-USA study, 
another recent large randomized controlled trial in ICU patients with delirium and acute respiratory failure or shock ( $n=1183$ patients), neither haloperidol nor ziprasidone treatment was associated with a difference in delirium duration

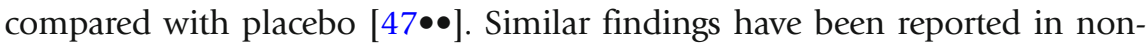
critically ill hospitalized adults, with a meta-analysis of 19 studies showing that antipsychotic use was not associated with lower delirium incidence, duration, or severity $[48 \bullet]$.

Expert guidelines, including those from the Society of Critical Care Medicine [30••] and the UK's National Institute for Health and Care Excellence (NICE) [49], therefore suggest that antipsychotics be reserved for short-term use for patients with agitation that poses a safety risk to themselves or others, or when a patient's hallucinations or other symptoms cause them significant distress. When antipsychotics are required, the lowest effective dosage should be used for the shortest duration possible. Commonly used antipsychotic medications for this purpose include haloperidol, quetiapine, and olanzapine (Table 3).

Advantages of haloperidol include the availability of parenteral administration via intramuscular and intravenous routes, a faster onset of action (within minutes when given parenterally), and a longer track record of experience in clinical use. However, as a typical antipsychotic, haloperidol may have a higher potential for extrapyramidal side effects, though there may not be a difference in risk with lower doses [51], and neither REDUCE nor MIND-USA found significantly higher rates of extrapyramidal symptoms in their large cohorts of patients. Similarly, though ECG QTc interval prolongation may also be a concern, these two large trials did not show a significantly increased risk with either low (3-6 mg daily in REDUCE) or moderate doses (up to $20 \mathrm{mg}$ daily in MIND-USA) of haloperidol. Atypical antipsychotics like quetiapine [52, 53] and olanzapine [54] may have similar efficacy to haloperidol in treating agitated delirium, while also potentially having a more favorable side effect profile, although these have been studied less extensively. Given their less prominent antagonism of dopamine receptors, quetiapine and olanzapine may pose a lower risk of extrapyramidal side effects, while their stronger affinity for histamine (and to a lesser extent, alpha-1) receptors typically leads to more sedation, which may be a desirable side effect in acutely agitated patients.

Table 3. Characteristics of antipsychotics commonly used in the ICU [50]

\begin{tabular}{|c|c|c|c|c|c|}
\hline Medication & Routes available & $\begin{array}{l}\text { Receptor affinity } \\
\text { Dopamine }\end{array}$ & Serotonin & Alpha-1 & Histamine \\
\hline Haloperidol & PO, IM, IV & +++ & + & + & - \\
\hline Quetiapine & $\mathrm{PO}$ & + & ++ & ++ & +++ \\
\hline Olanzapine & PO, IM, sublingual & ++ & +++ & + & +++ \\
\hline Ziprasidone & $\mathrm{PO}$ & ++ & +++ & + & + \\
\hline Risperidone & $\mathrm{PO}$ & +++ & +++ & ++ & ++ \\
\hline Aripiprazole & P0, IM & +++ & +++ & + & + \\
\hline
\end{tabular}


Acetylcholine has also been implicated in the pathogenesis of delirium [45], and it has been hypothesized that a shared common pathway of diminished cholinergic activity leading to cognitive dysfunction exists in both dementia and delirium [12]. Cholinesterase inhibitors, which are commonly used for patients with dementia, have therefore been considered as a potential delirium therapy, though initial results from small pilot studies were discouraging [55-57]. A subsequent larger randomized placebo-controlled trial of rivastigmine used as an adjunct to haloperidol suggested increased mortality and a longer duration of delirium in the rivastigmine group and was halted at an interim analysis because of safety concerns [58].

Sedation in the ICU may influence the development of subsequent delirium, although delirium that is primarily sedation-related and rapidly reversible appears not to carry the same adverse impact on outcomes as other forms of delirium [59]. Deep sedation appears to result in delayed extubation and increased mortality $[60,61]$ and may also play a role in the development of delirium. An overall strategy of maintaining light sedation as opposed to deep sedation is therefore recommended by the Society of Critical Care Medicine's clinical practice guidelines $[30 \bullet \bullet]$.

One method of maintaining light sedation in mechanically ventilated patients is with spontaneous awakening trials via daily interruption of sedative infusions. This may result in a decreased duration of mechanical ventilation and decreased ICU length of stay according to two randomized controlled trials [62, 63]. However, a more recent study that targeted lighter sedation levels found no benefit of sedation interruption compared with continuous sedation on delirium rates [64].

The choice of sedative agent appears to play a role in delirium incidence as well. Benzodiazepines in particular [65, 66], including lorazepam [67] and midazolam [68], were found to increase the likelihood of developing delirium. As a result, they have fallen out of favor as primary sedative agents in mechanically ventilated patients and patients with agitated delirium and should generally be avoided, except in cases of alcohol or benzodiazepine withdrawal.

In light of recent studies, dexmedetomidine-a centrally acting alpha-2adrenergic receptor agonist with sedative, anxiolytic, and analgesic-sparing properties-has emerged as an attractive alternative to other anesthetic and sedative agents due to perceived advantages in maintaining light sedation with a lower risk of causing adverse cognitive effects. In the MENDS trial, sedation with dexmedetomidine showed superiority to lorazepam in reducing deliriumand-coma-free days in mechanically ventilated ICU patients [69]. In the subsequent SEDCOM trial, which compared the efficacy and safety of prolonged sedation with dexmedetomidine vs. midazolam in mechanically ventilated ICU patients, the prevalence of delirium was significantly lower and the time to extubation was shorter in dexmedetomidine-treated patients compared with those who received midazolam, while rates of achieving target levels of sedation were similar in both groups [70]. Meanwhile, results of the PRODEX trial also 
suggest that sedation with dexmedetomidine may result in lower rates of delirium as compared with sedation with propofol [71], though delirium was not a predetermined outcome measure in the study, it was reported as part of a broader category of neurocognitive adverse effects and had only a 48-h period of follow-up after drug infusion.

Additionally, a recent placebo-controlled trial suggests that prophylactic nocturnal dexmedetomidine may reduce the incidence of delirium in ICU patients [72], a finding which warrants further study. On the other hand, prophylactic intraoperative dexmedetomidine does not appear to reduce the incidence of postoperative delirium based on the results of a trial in patients undergoing major elective noncardiac surgery [73].

Finally, dexmedetomidine may also be used as an acute treatment for agitated delirium, and its use in such cases may be associated with favorable effects. In the DahLIA study, in which dexmedetomidine or placebo was added to standard care in mechanically ventilated ICU patients with agitated delirium, dexmedetomidine was found to reduce ventilator-time and time to extubation,

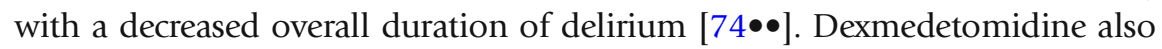
comes with the advantage of having minimal effects on respiratory drive, and it may therefore be a reasonable option to facilitate extubation in mechanically ventilated patients with agitation and to treat agitation in non-mechanically ventilated ICU patients. Common side effects of dexmedetomidine include bradycardia and, to a lesser extent, hypotension, but this usually does not preclude its use as agitation often coincides with hypertension and tachycardia. It should be noted that dexmedetomidine has a relatively higher cost compared with other sedatives used in the ICU; clonidine, a less selective alpha-2adrenergic receptor agonist, may represent a cheaper alternative, as it may also be an effective sedative for patients with agitated delirium [75].

Pain may be a significant risk factor for delirium [76, 77], although it may be difficult to disentangle the separate effects of opioid analgesics, which themselves may also be associated with increased delirium duration [66]. Meperidine may pose the highest risk for delirium among opioids [78] and should be avoided in high-risk patients.

Instead, nonopioid analgesics like acetaminophen should be used whenever possible, as they are less likely to cause or exacerbate delirium and are opioidsparing, though their effects may be limited in cases of severe pain. In the recent DEXACET study, a randomized clinical trial in patients undergoing cardiac surgery scheduled postoperative intravenous acetaminophen, which significantly reduced the incidence of in-hospital delirium and delirium duration (while also reducing opiate use for breakthrough analgesia) when used in combination with propofol or dexmedetomidine sedation [79••]. For patients without a contraindication (e.g., high bleeding risk or renal failure), nonsteroidal anti-inflammatory drugs may also be considered. Additionally, regional anesthesia may also be beneficial when pain is localized; for example, nerve blockades may be effective in reducing delirium rates in patients with hip fracture according to a systematic review [80].

Meanwhile, though ketamine has emerged as an alternative nonopioid sedative-analgesic in perioperative, emergency, and critical care settings, it 
may potentially precipitate delirium as it is known to cause hallucinations and other psychomimetic symptoms [81]. One retrospective study suggested that the possibility that these effects may be dose-dependent and that ketamine may actually attenuate delirium at subanesthetic doses [82]; however, a randomized controlled trial of subanesthetic intraoperative ketamine found no difference in the incidence of postoperative delirium while reporting more postoperative hallucinations with ketamine use [83].

Sleep disruption is highly prevalent in hospitalized patients [84] and has been posited as a possible risk factor for the development of delirium [85]. Pharmacologic interventions aimed at augmenting sleep therefore potentially represent an attractive target in the prevention and treatment of delirium, though data remains limited on the use of such medications.

The most studied of these is melatonin, which is a hormone naturally produced by the body for sleep-wake cycle regulation, and which also exists as an exogenous, synthetically-derived supplement. As a supplement, melatonin is not regulated by the Food and Drug Administration, however, thereby leading to potential inconsistency in dosage and effect. Such inconsistency may have contributed to the mixed results found thus far in studies of melatonin and delirium: a large multicenter placebo-controlled trial did not show any difference in delirium incidence between melatonin and placebo groups in patients with hip fracture [86], while a smaller single-center trial in elderly patients on a medicine ward did show a significantly decreased risk for delirium in those who received melatonin [87].

On the other hand, ramelteon is a highly selective melatonin receptor agonist that is FDA-approved and has been found to have a more consistent pharmacologic effect. Two small randomized placebo-controlled studies both found that ramelteon use was associated with a lower incidence of delirium in hospitalized patients $[88,89]$, and it may represent a key target of future larger studies.

Trazodone and quetiapine are other frequently used medications for insomnia in hospitalized patients [90]; however, their effects on delirium rates when used as sleep aids have not been studied. Benzodiazepines and non-benzodiazepine sedative hypnotics (e.g., zolpidem) are associated with increased rates of delirium and should not be used for this purpose, especially in older adults [91]. This class of drugs is known to suppress deeper stages of sleep and REM sleep [92], which may play a role in their deleterious effects.

Although no pharmacologic interventions have been proven to prevent or shorten the duration of delirium, there are many medications that may increase the risk of developing or worsening delirium. In addition to meperidine, benzodiazepines, and non-benzodiazepine sedative hypnotics, other medication classes to be avoided when possible include first-generation antihistamines (e.g., diphenhydramine, meclizine), tricyclic antidepressants (e.g., amitryptiline, imipramine), and other 
medications with anticholinergic properties (e.g., atropine, scopolamine) [93], as well as corticosteroids [94]. These and other high-risk medications have been compiled in the American Geriatrics Society's updated Beers criteria list of potentially inappropriate medications in older adults [91].

\section{Neurocritical care considerations}

As in other ICU populations, delirium is common in neurocritical care patients and is associated with longer ICU and hospital lengths of stay and worse functional outcomes $[95,96]$. However, patients with brain injury represent a unique challenge in delirium diagnosis due to their underlying neurological deficits, which may represent a barrier to conventional cognitive testing. Despite such challenges, even patients with aphasia, impaired arousal, and other deficits may meet DSM criteria for delirium with more inclusive definitions of inattention and other delirium features [97]. Existing ICU delirium screening tools may lack the nuance necessary to make these distinctions, however, and as a result, such tools have insufficient accuracy in neurocritical care settings [18] and in patients with brain injury [98]. The ICDSC may be a more suitable and accurate tool than the CAM-ICU in the neurocritical care unit due to its inclusion of delirium features obtainable by observation rather than verbal testing [97, 99], but novel delirium screening tools may be warranted in patients with severe neurological injury.

Neurocritical care populations are also unique in that the etiology of their delirium may be a direct consequence of their underlying brain injury, either due to primary effects or subsequent complications such as hydrocephalus, cerebral edema, intracranial hypertension, seizures, hypoperfusion, or cerebral ischemia $[100,101]$. There is indeed a high prevalence of neurological deterioration in patients with acute brain injury, a risk which typically warrants frequent, often hourly, neurological examinations and a low threshold to perform clinically appropriate diagnostic testing. However, though the frequency of examinations may be more likely to capture clinical changes soon after they occur, it may also be paradoxically harmful to patients if it leads to sleep deprivation and subsequent delirium [102]. As a result, the frequency of examinations should be moderated as soon as a patient is no longer thought to be at high risk of neurological deterioration due to their brain injury.

Management of delirium in the neurocritical care unit has been largely extrapolated from other ICU settings. However, trials of pharmacological treatments of delirium in the ICU have typically excluded patients with a neurological critical illness, and there is therefore little high-quality evidence to guide treatment. A goal of sedation in the neurocritical care unit is often to achieve anxiolysis and analgesia without compromising arousal or other features of the neurological examination, and dexmedetomidine may be more likely than propofol or other sedative infusions to allow for such balance [103]. A systematic review of alpha-2 agonists for sedation in mechanically ventilated neurocritical care patients showed that the use of 


\section{Conclusion}

dexmedetomidine and clonidine appeared safe from the standpoint of systemic and cerebral hemodynamics, but there was insufficient data regarding possible effectiveness [104]. On the other hand, while antipsychotics have been shown to be ineffective in shortening delirium duration in non-neurological ICU patients, they may carry additional risks for patients in the neurocritical care unit, as antidopaminergic agents have been shown to impede recovery after brain injury in animal models [105, 106].

Delirium remains a prevalent complication in critically ill patients that comes with serious consequences, and for which, there remain few effective treatment options. Multicomponent non-pharmacologic interventions likely represent the best strategies for delirium prevention, with real-world evidence favoring the use of the ABCDEF bundle. Avoiding high-risk medications such as benzodiazepines and anticholinergics is also of paramount importance, especially in older patients. Other pharmacologic prevention strategies have mostly proven disappointing, though aggressive treatment of pain with nonopioid analgesics is encouraged, while the use of prophylactic antipsychotics is discouraged based on current evidence. Antipsychotics should be reserved for the treatment of delirium that is accompanied by severe agitation or psychotic features and should be prescribed cautiously, at the lowest dose and shortest duration deemed necessary. Meanwhile, dexmedetomidine may be effective as an adjunctive treatment for agitation and may also be a preferred agent for sedation of mechanically ventilated patients. Most importantly, when delirium does occur, possible underlying sources of delirium should be investigated and promptly treated if identified.

\section{Compliance with Ethical Standards}

\section{Conflict of Interest}

Michael E. Reznik declares no potential conflicts of interest.

Arjen J.C. Slooter reports grants and non-financial support from Prolira, a start-up company that develops an EEGbased delirium monitor. Dr. Slooter is an advisor for Prolira. Any (future) profits from EEG-based delirium monitoring will be used for future scientific research only. In addition, Dr. Slooter has a patent "Method and system for determining a parameter which is indicative for whether a patient is delirious" (application no.: PCT/EP2013/ 069521, Filed September 19, 2013); pending.

\section{Human and Animal Rights and Informed Consent}

This article does not contain any studies with human or animal subjects performed by any of the authors. 


\section{References and Recommended Reading}

Papers of particular interest, published recently, have been highlighted as:

- Of importance

$\bullet \quad$ Of major importance

1. Salluh JIF, Wang H, Schneider EB, Nagaraja N, Yenokyan G, Damluji A, et al. Outcome of delirium in critically ill patients: systematic review and meta-analysis. The BMJ. 2015;350:h2538. https://doi.org/10. 1136/bmj.h2538.

2. Ely EW, Inouye SK, Bernard GR, Gordon S, Francis J, May L. Delirium in mechanically ventilated patients: validity and reliability of the confusion assessment method for the intensive care unit (CAM-ICU). JAMA. 2001;286:2703-10. https://doi.org/10.1001/jama. 286.21.2703.

3. Ely E, Shintani A, Truman B, Speroff T, Gordon SM, Harrell FE Jr, et al. Delirium as a predictor of mortality in mechanically ventilated patients in the intensive care unit. JAMA. 2004;291(14):1753-62. https://doi.org/ 10.1001/jama.291.14.1753.

4. Girard TD, Jackson JC, Pandharipande PP, Pun BT, Thompson JL, Shintani AK, et al. Delirium as a predictor of long-term cognitive impairment in survivors of critical illness. Crit Care Med. 2010;38(7):1513-20. https://doi.org/10.1097/CCM.0b013e3181e47be1.

5. van den Boogaard M, Schoonhoven L, Evers AWM, van der Hoeven JG, van Achterberg T, Pickkers P. Delirium in critically ill patients: impact on long-term healthrelated quality of life and cognitive functioning*. Crit Care Med. 2012;40(1):112-8. https://doi.org/10. 1097/CCM.0b013e31822e9fc9.

6. Pandharipande PP, Girard TD, Jackson JC, Morandi A, Thompson JL, Pun BT, et al. Long-term cognitive impairment after critical illness. N Engl J Med. 2013;369(14):1306-16. https://doi.org/10.1056/ NEJMoa1301372.

7. Klein Klouwenberg PMC, Zaal IJ, Spitoni C, Ong DSY, van der Kooi AW, Bonten MJM, et al. The attributable mortality of delirium in critically ill patients: prospective cohort study. BMJ : British Medical Journal. 2014;349:g6652. https://doi.org/10.1136/bmj.g6652.

8. Wolters AE, van Dijk D, Pasma W, Cremer OL, Looije $\mathrm{MF}$, de Lange DW, et al. Long-term outcome of delirium during intensive care unit stay in survivors of critical illness: a prospective cohort study. Crit Care. 2014;18(3):R125. https://doi.org/10.1186/cc13929.

9. Fong TG, Davis D, Growdon ME, Albuquerque A, Inouye SK. The Interface of delirium and dementia in older persons. The Lancet Neurology. 2015;14(8):82332. https://doi.org/10.1016/S1474-4422(15)00101-5.

10. Tow A, Holtzer R, Wang C, Sharan A, Kim SJ, Gladstein $A$, et al. Cognitive reserve and postoperative delirium in older adults. J Am Geriatr Soc. 2016;64(6):1341-6. https://doi.org/10.1111/jgs.14130.
11. Cizginer S, Marcantonio E, Vasunilashorn S, PascualLeone A, Shafi M, Schmitt EM, et al. The cognitive reserve model in the development of delirium: the successful aging after elective surgery study. J Geriatr Psychiatry Neurol. 2017;30(6):337-45. https://doi. org/10.1177/0891988717732152.

12. Hshieh TT, Fong TG, Marcantonio ER, Inouye SK. Cholinergic deficiency hypothesis in delirium: a synthesis of current evidence. J Gerontol A Biol Sci Med Sci. 2008;63(7):764-72. https://doi.org/10.1093/ gerona/63.7.764.

13. Maldonado JR. Neuropathogenesis of delirium: review of current etiologic theories and common pathways. Am J Geriatr Psychiatry. 2013;21(12):1190-222. https://doi.org/10.1016/j.jagp.2013.09.005.

14. van Dellen E, van der Kooi AW, Numan T, Koek HL, Klijn FA, Buijsrogge MP, et al. Decreased functional connectivity and disturbed directionality of information flow in the electroencephalography of intensive care unit patients with delirium after cardiac surgery. Anesthesiology. 2014;121(2):328-35. https://doi.org/ 10.1097/aln.0000000000000329.

15. Munster BCV, Aronica E, Zwinderman AH, Eikelenboom P, Cunningham C, Rooij SE. Neuroinflammation in delirium: a postmortem case-control study. Rejuvenation Res. 2011;14(6):615-22. https:// doi.org/10.1089/rej.2011.1185.

16. Diagnostic and statistical manual of mental disorders: DSM-5. Fifth edition. Arlington : American Psychiatric Association, (2013); 2013.

17. Bergeron N, Dubois MJ, Dumont M, Dial S, Skrobik Y. Intensive care delirium screening checklist: evaluation of a new screening tool. Intensive Care Med. 2001;27(5):859-64.

18. Eijk MMV, Boogaard MVD, Marum RJV, Benner P, Eikelenboom $\mathrm{P}$, Honing ML, et al. Routine use of the confusion assessment method for the intensive care unit. Am J Respir Crit Care Med. 2011;184(3):340-4. https://doi.org/10.1164/rccm.201101-0065OC.

19. Morandi A, Davis D, Bellelli G, Arora RC, Caplan GA, Kamholz B, et al. The diagnosis of delirium superimposed on dementia: an emerging challenge. J Am Med Dir Assoc. 2017;18(1):12-8. https://doi.org/ 10.1016/j.jamda.2016.07.014.

20. Inouye SK, Leo-Summers L, Zhang Y, Bogardus ST Jr, Leslie DL, Agostini JV. A chart-based method for identification of delirium: validation compared with interviewer ratings using the confusion assessment method. J Am Geriatr Soc. 2005;53(2):312-8. https://doi.org/ 10.1111/j.1532-5415.2005.53120.x. 
21. Ahmed S, Leurent B, Sampson EL. Risk factors for incident delirium among older people in acute hospital medical units: a systematic review and meta-analysis. Age Ageing. 2014;43(3):326-33. https://doi.org/ 10.1093/ageing/afu022.

22. Zaal IJ, Devlin JW, Peelen LM, Slooter AJC. A systematic review of risk factors for delirium in the ICU* . Crit Care Med. 2015;43(1):40-7. https://doi.org/10.1097/ccm. 0000000000000625.

23. Wassenaar A, van den Boogaard $M$, van Achterberg T, Slooter AJC, Kuiper MA, Hoogendoorn ME, et al. Multinational development and validation of an early prediction model for delirium in ICU patients. Intensive Care Med. 2015;41(6):1048-56. https://doi.org/ 10.1007/s00134-015-3777-2.

24. van den Boogaard M, Pickkers P, Slooter AJC, Kuiper MA, Spronk PE, van den Voort PHJ, et al. Development and validation of PRE-DELIRIC (PREdiction of DELIRium in ICu patients) delirium prediction model for intensive care patients: observational multicentre study. BMJ. 2012;344:e420. https://doi.org/10.1136/ bmj.e420.

25. Inouye SK, Bogardus ST, Charpentier PA, Leo-Summers L, Acampora D, Holford TR, et al. A multicomponent intervention to prevent delirium in hospitalized older patients. N Engl J Med. 1999;340(9):669-76. https:// doi.org/10.1056/nejm199903043400901.

26. Hshieh TT, Yang T, Gartaganis SL, Yue J, Inouye SK. Hospital elder life program: systematic review and meta-analysis of effectiveness. Am J Geriatr Psychiatry. 2018;26(10):1015-33. https://doi.org/10.1016/j.jagp. 2018.06.007.

27. Hshieh TT, Yue J, Oh E, Puelle M, Dowal S, Travison T, et al. Effectiveness of multicomponent nonpharmacological delirium interventions: a metaanalysis of delirium prevention. JAMA Intern Med. 2015;175(4):512-20. https://doi.org/10.1001/ jamainternmed.2014.7779.

28. Siddiqi N, Harrison JK, Clegg A, Teale EA, Young J, Taylor J, et al. Interventions for preventing delirium in hospitalised non-ICU patients. Cochrane Database Syst Rev. 2016;(3). https://doi.org/10.1002/14651858. CD005563.pub3.

29. Bannon L, Mc Gaughey J, Verghis R, Clarke M, Mc Auley DF, Blackwood B. The effectiveness of nonpharmacological interventions in reducing the incidence and duration of delirium in critically ill patients: a systematic review and meta-analysis. Intensive Care Med. 2018;45(1):1-12.

A comprehensive systematic review and meta-analysis of clinical studies for single- and multi-component non-pharmacological interventions to prevent delirium in ICU patients.

30.• Devlin JW, Skrobik Y, Gélinas C, Needham DM, Slooter AJC, Pandharipande PP, et al. Clinical practice guidelines for the prevention and management of pain, agitation/sedation, delirium, immobility, and sleep disruption in adult patients in the ICU. Crit Care Med. 2018;46(9):e825-e73. https://doi.org/10.1097/ccm. 0000000000003299 .
A wide-ranging and recently updated set of clinical practice guidelines on the management of delirium and deliriumrelated issues in the ICU by the Society for Critical Care Medicine.

31. Marra A, Ely EW, Pandharipande PP, Patel MB. The ABCDEF bundle in critical care. Crit Care Clin. 2017;33(2):225-43. https://doi.org/10.1016/j.ccc. 2016.12.005.

32. Balas MC, Vasilevskis EE, Olsen KM, Schmid KK, Shostrom V, Cohen MZ, et al. Effectiveness and safety of the awakening and breathing coordination, delirium monitoring/management, and early exercise/ mobility bundle* . Crit Care Med. 2014;42(5):102436. https://doi.org/10.1097/ccm.0000000000000129.

33. Barnes-Daly MA, Phillips G, Ely EW. Improving hospital survival and reducing brain dysfunction at seven California community hospitals: implementing PAD guidelines via the ABCDEF bundle in 6,064 patients* Crit Care Med. 2017;45(2):171-8. https://doi.org/10. 1097/ccm.0000000000002149.

34. Pun BT, Balas MC, Barnes-Daly MA, Thompson JL, Aldrich JM, Barr J, et al. Caring for critically ill patients with the ABCDEF bundle: results of the ICU liberation collaborative in over 15,000 adults. Crit Care Med. 2019;47(1):3-14. https://doi.org/10.1097/ccm. 0000000000003482.

A large prospective multi-center quality improvement study showing that ABCDEF bundle adherence was associated with improved ICU outcomes, including a lower likelihood of delirium.

35. Morandi A, Piva S, Ely EW, Myatra SN, Salluh JIF, Amare D, et al. Worldwide survey of the "Assessing pain, both spontaneous awakening and breathing trials, choice of drugs, delirium monitoring/management, early exercise/mobility, and family empowerment" (ABCDEF). Bundle Critical Care Medicine. 2017;45(11):e1111-e22. https://doi.org/10.1097/ ccm.0000000000002640.

36. Schweickert WD, Pohlman MC, Pohlman AS, Nigos C, Pawlik AJ, Esbrook CL, et al. Early physical and occupational therapy in mechanically ventilated, critically ill patients: a randomised controlled trial. Lancet. 2009;373(9678):1874-82. https://doi.org/10.1016/ S0140-6736(09)60658-9.

37. Álvarez EA, Garrido MA, Tobar EA, Prieto SA, Vergara $\mathrm{SO}$, Briceño CD, et al. Occupational therapy for delirium management in elderly patients without mechanical ventilation in an intensive care unit: a pilot randomized clinical trial. J Crit Care. 2017;37:85-90. https://doi.org/10.1016/j.jcrc.2016.09.002.

38. Zaal IJ, Spruyt CF, Peelen LM, van Eijk MMJ, Wientjes $\mathrm{R}$, Schneider MME, et al. Intensive care unit environment may affect the course of delirium. Intensive Care Med. 2013;39(3):481-8. https://doi.org/10.1007/ s00134-012-2726-6.

39. Litton E, Carnegie V, Elliott R, Webb SAR. The efficacy of earplugs as a sleep hygiene strategy for reducing delirium in the ICU: a systematic review and meta- 
analysis*. Crit Care Med. 2016;44(5):992-9. https:// doi.org/10.1097/ccm.0000000000001557.

40. Inouye SK, Zhang Y, Jones RN, Kiely DK, Yang F, Marcantonio ER. Risk factors for delirium at discharge: development and validation of a predictive model. JAMA Intern Med. 2007;167(13):1406-13. https://doi. org/10.1001/archinte.167.13.1406.

41. Colombo R, Corona A, Praga F, Minari C, Giannotti C, Castelli A, et al. A reorientation strategy for reducing delirium in the critically ill. Results of an interventional study. Minerva Anestesiol. 2012;78(9):1026-33.

42. Munro CL, Cairns P, Ji M, Calero K, Anderson WM, Liang Z. Delirium prevention in critically ill adults through an automated reorientation intervention: a pilot randomized controlled trial. Heart \& Lung: The Journal of Cardiopulmonary and Acute Care. 2017;46(4):234-8. https://doi.org/10.1016/j.hrtlng. 2017.05.002.

43. Marcantonio ER, Flacker JM, Wright RJ, Resnick NM. Reducing delirium after hip fracture: a randomized trial. J Am Geriatr Soc. 2001;49(5):516-22. https://doi. org/10.1046/j.1532-5415.2001.49108.x.

44. Björkelund KB, Hommel A, Thorngren K-G, Gustafson L, Larsson S, Lundberg D. Reducing delirium in elderly patients with hip fracture: a multi-factorial intervention study. Acta Anaesthesiol Scand. 2010;54(6):678-88. https://doi.org/10.1111/j.1399-6576.2010.02232.x.

45. Trzepacz PT. Is there a final common neural pathway in delirium? Focus on acetylcholine and dopamine. Semin Clin Neuropsychiatry. 2000;5(2):132-48.

46.• van den Boogaard M, Slooter AJC, Brüggemann RJM, Schoonhoven L, Beishuizen A, Vermeijden JW, et al. Effect of haloperidol on survival among critically ill adults with a high risk of delirium: the REDUCE randomized clinical trial. JAMA. 2018;319(7):680-90. https://doi.org/10.1001/jama.2018.0160.

One of two recent randomized clinical trials that found that antipsychotics - in this case haloperidol-were ineffective in ICU patients. This study showed that delirium could not be prevented with haloperidol.

47.• Girard TD, Exline MC, Carson SS, Hough CL, Rock P, Gong MN, et al. Haloperidol and ziprasidone for treatment of delirium in critical illness. N Engl J Med. 2018;379(26):2506-16. https://doi.org/10.1056/ NEJMoa1808217.

One of two recent randomized clinical trials that found that antipsychotics-in this case haloperidol and ziprasidone-were ineffective in ICU patients. This study showed that delirium duration could not be shorted with antipsychotics.

48. Neufeld KJ, Yue J, Robinson TN, Inouye SK, Needham DM. Antipsychotic medication for prevention and treatment of delirium in hospitalized adults: a systematic review and meta-analysis. J Am Geriatr Soc. 2016;64(4):705-14. https://doi.org/10.1111/jgs. 14076.

A comprehensive systematic review and meta-analysis of clinical studies for the use of antipsychotics to prevent and treat delirium in hospitalized patients.
49. Young J, Murthy L, Westby M, Akunne A, O'Mahony R. Diagnosis, prevention, and management of delirium: summary of NICE guidance. BMJ. 2010;341:c3704. https://doi.org/10.1136/bmj.c3704.

50. Siafis S, Tzachanis D, Samara M, Papazisis G. Antipsychotic drugs: from receptor-binding profiles to metabolic side effects. Curr Neuropharmacol. 2018;16(8):1210-23. https://doi.org/10.2174/ $1570159 X 15666170630163616$.

51. Lonergan E, Britton AM, Luxenberg J. Antipsychotics for delirium. Cochrane Database Syst Rev 2007(2). doi:https://doi.org/10.1002/14651858.CD005594. pub2.

52. Devlin JW, Roberts RJ, Fong JJ, Skrobik Y, Riker RR, Hill NS, et al. Efficacy and safety of quetiapine in critically ill patients with delirium: a prospective, multicenter, randomized, double-blind, placebo-controlled pilot study*. Crit Care Med. 2010;38(2):419-27. https:// doi.org/10.1097/CCM.0b013e3181b9e302.

53. Hawkins SB, Bucklin M, Muzyk AJ. Quetiapine for the treatment of delirium. J Hosp Med. 2013;8(4):215-20. https://doi.org/10.1002/jhm.2019.

54. Skrobik YK, Bergeron N, Dumont M, Gottfried SB. Olanzapine vs haloperidol: treating delirium in a critical care setting. Intensive Care Med. 2004;30(3):4449. https://doi.org/10.1007/s00134-003-2117-0.

55. Liptzin B, Laki A, Garb JL, Fingeroth R, Krushell R. Donepezil in the prevention and treatment of postsurgical delirium. Am J Geriatr Psychiatry. 2005;13(12):1100-6. https://doi.org/10.1097/ 00019442-200512000-00010.

56. Sampson EL, Raven PR, Ndhlovu PN, Vallance A, Garlick N, Watts J, et al. A randomized, double-blind, placebo-controlled trial of donepezil hydrochloride (Aricept) for reducing the incidence of postoperative delirium after elective total hip replacement. Int J Geriatric Psychiatry. 2007;22(4):343-9. https://doi.org/ 10.1002/gps.1679.

57. Marcantonio ER, Palihnich K, Appleton P, Davis RB. Pilot randomized trial of donepezil hydrochloride for delirium after hip fracture. J Am Geriatr Soc. 2011;59(s2):S282-S8. https://doi.org/10.1111/j. 1532-5415.2011.03691.x.

58. van Eijk MMJ, Roes KCB, Honing MLH, Kuiper MA, Karakus A, van der Jagt $M$, et al. Effect of rivastigmine as an adjunct to usual care with haloperidol on duration of delirium and mortality in critically ill patients: a multicentre, double-blind, placebo-controlled randomised trial. Lancet. 2010;376(9755):1829-37. https://doi.org/10.1016/S0140-6736(10)61855-7.

59. Patel SB, Poston JT, Pohlman A, Hall JB, Kress JP. Rapidly reversible, sedation-related delirium versus persistent delirium in the intensive care unit. Am J Respir Crit Care Med. 2014;189(6):658-65. https:// doi.org/10.1164/rccm.201310-1815OC.

60. Shehabi Y, Bellomo R, Reade MC, Bailey M, Bass F, Howe $\mathrm{B}$, et al. Early intensive care sedation predicts long-term mortality in ventilated critically ill patients. 
Am J Respir Crit Care Med. 2012;186(8):724-31. https://doi.org/10.1164/rccm.201203-0522OC.

61. Shehabi Y, Chan L, Kadiman S, Alias A, Ismail WN, Tan MATI, et al. Sedation depth and long-term mortality in mechanically ventilated critically ill adults: a prospective longitudinal multicentre cohort study. Intensive Care Med. 2013;39(5):910-8. https://doi.org/10. 1007/s00134-013-2830-2.

62. Kress JP, Pohlman AS, O'Connor MF, Hall JB. Daily interruption of sedative infusions in critically ill patients undergoing mechanical ventilation. $\mathrm{N}$ Engl J Med. 2000;342(20):1471-7. https://doi.org/10.1056/ nejm200005183422002.

63. Girard TD, Kress JP, Fuchs BD, Thomason JW, Schweickert WD, Pun BT, et al. Efficacy and safety of a paired sedation and ventilator weaning protocol for mechanically ventilated patients in intensive care (awakening and breathing controlled trial): a randomised controlled trial. Lancet. 2008;371(9607):126-34. https://doi.org/10.1016/ s0140-6736(08)60105-1.

64. Mehta S, Burry L, Cook D, Fergusson D, Steinberg M, Granton J, et al. Daily sedation interruption in mechanically ventilated critically ill patients cared for with a sedation protocol: a randomized controlled trial. JAMA. 2012;308(19):1985-92. https://doi.org/10. 1001/jama.2012.13872.

65. Zaal IJ, Devlin JW, Hazelbag M, Klein Klouwenberg PMC, van der Kooi AW, Ong DSY, et al. Benzodiazepine-associated delirium in critically ill adults. Intensive Care Med. 2015;41(12):2130-7. https://doi.org/10.1007/s00134-015-4063-z.

66. Pisani MA, Murphy TE, Araujo KLB, Slattum P, Van Ness PH, Inouye SK. Benzodiazepine and opioid use and the duration of intensive care unit delirium in an older population*. Crit Care Med. 2009;37(1):17783. https://doi.org/10.1097/CCM.0b013e318192fff9.

67. Pandharipande P, Shintani A, Peterson J, Pun BT, Wilkinson GR, Dittus RS, et al. Lorazepam is an independent risk factor for transitioning to delirium in intensive care unit patients. Anesthesiology: The Journal of the American Society of Anesthesiologists.

2006;104(1):21-6.

68. Pandharipande P, Cotton BA, Shintani A, Thompson J, Pun BT, Morris JAJ, et al. Prevalence and risk factors for development of delirium in surgical and trauma intensive care unit patients. J Trauma Acute Care Surg. 2008;65(1):34-41. https://doi.org/10.1097/TA. 0b013e31814b2c4d.

69. Pandharipande PP, Pun BT, Herr DL, Maze M, Girard TD, Miller RR, et al. Effect of sedation with dexmedetomidine vs lorazepam on acute brain dysfunction in mechanically ventilated patients the MENDS randomized controlled trial. JAMA. 2007;298(22):2644-53. https://doi.org/10.1001/ jama.298.22.2644.

70. Riker RR, Shehabi Y, Bokesch PM, Ceraso D, Wisemandle W, Koura F, et al. Dexmedetomidine vs midazolam for sedation of critically ill patients: a randomized trial. JAMA. 2009;301(5):489-99. https:// doi.org/10.1001/jama.2009.56.

71. Jakob SM, Ruokonen E, Grounds RM, Sarapohja T, Garratt C, Pocock SJ, et al. Dexmedetomidine vs midazolam or propofol for sedation during prolonged mechanical ventilation: two randomized controlled trials. JAMA. 2012;307(11):1151-60. https://doi.org/ 10.1001/jama.2012.304.

72. Skrobik Y, Duprey MS, Hill NS, Devlin JW. Low-dose nocturnal dexmedetomidine prevents ICU delirium. A randomized, placebo-controlled trial. Am J Respir Crit Care Med. 2018;197(9):1147-56. https://doi.org/10. 1164/rccm.201710-1995OC.

73. Deiner S, Luo X, Lin H-M, Sessler DI, Saager L, Sieber $\mathrm{FE}$, et al. Intraoperative infusion of dexmedetomidine for prevention of postoperative delirium and cognitive dysfunction in elderly patients undergoing major elective noncardiac surgery: a randomized clinical trial. JAMA Surgery. 2017;152(8):e171505. https://doi.org/ 10.1001/jamasurg.2017.1505.

74.• Reade MC, Eastwood GM, Bellomo R, Bailey M, Bersten A, Cheung B, et al. Effect of dexmedetomidine added to standard care on ventilator-free time in patients with agitated delirium: a randomized clinical trial. JAMA. 2016;315(14):1460-8. https://doi.org/10. 1001/jama.2016.2707.

A randomized clinical trial that found dexmedetomidine was effective in shortening the duration of delirium in agitated ICU patients when added to standard care.

75. Gagnon DJ, Riker RR, Glisic EK, Kelner A, Perrey HM, Fraser GL. Transition from dexmedetomidine to enteral clonidine for ICU sedation: an observational pilot study. Pharmacotherapy: The Journal of Human Pharmacology and Drug Therapy. 2015;35(3):251-9. https://doi.org/10.1002/phar.1559.

76. Morrison RS, Magaziner J, Gilbert M, Koval KJ, McLaughlin MA, Orosz G, et al. Relationship between pain and opioid analgesics on the development of delirium following hip fracture. J Gerontol: Series A. 2003;58(1):M76-81. https://doi.org/10.1093/gerona/ 58.1.M76.

77. Feast AR, White N, Lord K, Kupeli N, Vickerstaff V, Sampson EL. Pain and delirium in people with dementia in the acute general hospital setting. Age Ageing. 2018;47(6):841-6. https://doi.org/10.1093/ ageing/afy 112 .

78. Marcantonio ER, Juarez G, Goldman L, Mangione CM, Ludwig LE, Lind L, et al. The relationship of postoperative delirium with psychoactive medications. JAMA. 1994;272(19):1518-22. https://doi.org/10.1001/ jama.1994.03520190064036.

79.• Subramaniam B, Shankar P, Shaefi S, Mueller A, O'Gara B, Banner-Goodspeed V, et al. Effect of intravenous acetaminophen vs placebo combined with propofol or dexmedetomidine on postoperative delirium among older patients following cardiac surgery: the DEXACET randomized clinical trial. JAMA. 2019;321(7):686-96. https://doi.org/10.1001/jama. 2019.0234 . 
A randomized clinical trial that found scheduled intravenous acetaminophen was effective in preventing post-operative delirium, emphasizing the importance of nonopioid analgesia in delirium management.

80. Abou-Setta AM, Beaupre LA, Rashiq S, Dryden DM, Hamm MP, Sadowski CA, et al. Comparative effectiveness of pain management interventions for hip fracture: a systematic review. Ann Intern Med. 2011;155(4):234-45. https://doi.org/10.7326/00034819-155-4-201108160-00346.

81. Erstad BL, Patanwala AE. Ketamine for analgosedation in critically ill patients. J Crit Care. 2016;35:145-9. https://doi.org/10.1016/j.jcrc.2016.05.016.

82. Hudetz JA, Patterson KM, Iqbal Z, Gandhi SD, Byrne AJ, Hudetz AG, et al. Ketamine attenuates delirium after cardiac surgery with cardiopulmonary bypass. J Cardiothorac Vasc Anesth. 2009;23(5):651-7. https:// doi.org/10.1053/j.jvca.2008.12.021.

83. Avidan MS, Maybrier HR, Abdallah AB, Jacobsohn E, Vlisides PE, Pryor KO, et al. Intraoperative ketamine for prevention of postoperative delirium or pain after major surgery in older adults: an international, multicentre, double-blind, randomised clinical trial. Lancet. 2017;390(10091):267-75. https://doi.org/10. 1016/S0140-6736(17)31467-8.

84. Wesselius HM, van den Ende ES, Alsma J, ter Maaten JC, Schuit SCE, Stassen PM, et al. Quality and quantity of sleep and factors associated with sleep disturbance in hospitalized patients. JAMA Intern Med. 2018;178(9):1201-8. https://doi.org/10.1001/ jamainternmed.2018.2669.

85. Evans JL, Nadler JW, Preud'homme XA, Fang E, Daughtry RL, Chapman JB, et al. Pilot prospective study of post-surgery sleep and EEG predictors of postoperative delirium. Clin Neurophysiol.

2017;128(8):1421-5. https://doi.org/10.1016/j. clinph.2017.05.004.

86. de Jonghe A, van Munster BC, Goslings JC, Kloen P, van Rees C, Wolvius R, et al. Effect of melatonin on incidence of delirium among patients with hip fracture: a multicentre, double-blind randomized controlled trial. Can Med Assoc J. 2014;186(14):E547-E56. https://doi.org/10.1503/cmaj.140495.

87. Al-Aama T, Brymer C, Gutmanis I, WoolmoreGoodwin SM, Esbaugh J, Dasgupta M. Melatonin decreases delirium in elderly patients: a randomized, placebo-controlled trial. In J Geriatric Psychiatry. 2011;26(7):687-94. https://doi.org/10.1002/gps. 2582.

88. Hatta K, Kishi Y, Wada K, Takeuchi T, Odawara T, Usui $\mathrm{C}$, et al. Preventive effects of ramelteon on delirium: a randomized placebo-controlled trial. JAMA Psychiatry. 2014;71(4):397-403. https://doi.org/10.1001/ jamapsychiatry.2013.3320.

89. Nishikimi M, Numaguchi A, Takahashi K, Miyagawa $Y$, Matsui K, Higashi M, et al. Effect of administration of ramelteon, a melatonin receptor agonist, on the duration of stay in the ICU: a single-center randomized placebo-controlled trial*. Crit Care Med.
2018;46(7):1099-105. https://doi.org/10.1097/ccm. 0000000000003132

90. Gillis CM, Poyant JO, Degrado JR, Ye L, Anger KE, Owens RL. Inpatient pharmacological sleep aid utilization is common at a tertiary medical center. J Hosp Med. 2014;9(10):652-7. https://doi.org/10.1002/jhm. 2246.

91. American Geriatrics Society 2015. Updated beers criteria for potentially inappropriate medication use in older adults. J Am Geriatr Soc. 2015;63(11):2227-46. https://doi.org/10.1111/jgs.13702.

92. Roehrs T, Roth T. Drug-related sleep stage changes: functional significance and clinical relevance. Sleep Med Clin. 2010;5(4):559-70. https://doi.org/10.1016/ j.jsmc.2010.08.002.

93. Han L, McCusker J, Cole M, Abrahamowicz M, Primeau F, Élie M. Use of medications with anticholinergic effect predicts clinical severity of delirium symptoms in older medical inpatients. JAMA Intern Med. 2001;161(8):1099-105. https://doi.org/10. 1001/archinte.161.8.1099.

94. Schreiber MP, Colantuoni E, Bienvenu OJ, Neufeld KJ, Chen K-F, Shanholtz C, et al. Corticosteroids and transition to delirium in patients with acute lung injury*. Crit Care Med. 2014;42(6):1480-6. https://doi. org/10.1097/ccm.0000000000000247.

95. Patel MB, Bednarik J, Lee P, Shehabi Y, Salluh JI, Slooter AJ, et al. Delirium monitoring in neurocritically ill patients: a systematic review*. Crit Care Med. 2018;46(11):1832-41. https://doi.org/10.1097/ccm. 0000000000003349.

96. Shi Q, Presutti R, Selchen D, Saposnik G. Delirium in acute stroke: a systematic review and meta-analysis. Stroke. 2012;43(3):645-9. https://doi.org/10.1161/ strokeaha.111.643726.

97. Reznik ME, Drake J, Margolis SA, Moody S, Murray K, Costa $\mathrm{S}$ et al. Deconstructing post-stroke delirium in a prospective cohort of patients with intracerebral hemorrhage. Critical Care Med 2019;Publication pending.

98. Frenette AJ, Bebawi ER, Deslauriers LC, Tessier A-AL, Perreault MM, Delisle M-S, et al. Validation and comparison of CAM-ICU and ICDSC in mild and moderate traumatic brain injury patients. Intensive Care Med. 2016;42(1):122-3. https://doi.org/10.1007/s00134015-3964-1.

99. Larsen LK, Frøkjær VG, Nielsen JS, Skrobik Y, Winkler $\mathrm{Y}$, Møller K, et al. Delirium assessment in neurocritically ill patients: a validation study. Acta Anaesthesiol Scand. 2019;63(3):352-9. https://doi. org/10.1111/aas.13270.

100. Frontera JA. Delirium and sedation in the ICU. Neurocrit Care. 2011;14(3):463-74. https://doi.org/ 10.1007/s12028-011-9520-0.

101. Reznik ME, Schmidt JM, Mahta A, Agarwal S, Roh DJ, Park S, et al. Agitation after subarachnoid hemorrhage: a frequent omen of hospital complications associated with worse outcomes. Neurocrit Care. 2016;26:1-8. https://doi.org/10.1007/s12028-0160331-1. 
102. McLaughlin DC, Hartjes TM, Freeman WD. Sleep deprivation in neurointensive care unit patients from serial neurological checks: how much is too much? J Neurosci Nurs. 2018;50(4):205-10. https://doi.org/ $10.1097 /$ jnn.0000000000000378.

103. Mirski MA, Lewin JJ, LeDroux S, Thompson C, Murakami P, Zink EK, et al. Cognitive improvement during continuous sedation in critically ill, awake and responsive patients: the acute neurological ICU sedation trial (ANIST). Intensive Care Med. 2010;36(9):1505-13. https://doi.org/10.1007/ s00134-010-1874-9.

104. Tran A, Blinder H, Hutton B, English SW. A systematic review of alpha-2 agonists for sedation in mechanically ventilated neurocritical care patients. Neurocrit Care. 2018;28(1):12-25. https://doi.org/10.1007/ s12028-017-0388-5.
105. Feeney D, Gonzalez A, Law W. Amphetamine, haloperidol, and experience interact to affect rate of recovery after motor cortex injury. Science. 1982;217(4562):855-7. https://doi.org/10.1126/ science.7100929.

106. Goldstein LB, Bullman S. Differential effects of haloperidol and clozapine on motor recovery after sensorimotor cortex injury in rats. Neurorehabil Neural Repair. 2002;16(4):321-5. https://doi.org/10.1177/ 154596830201600402.

\section{Publisher's Note}

Springer Nature remains neutral with regard to jurisdictional claims in published maps and institutional affiliations 